Research Paper

\title{
Could Somatostatin Enhance the Outcomes of Chemotherapeutic Treatment in SCLC?
}

\author{
Kalliopi Domvri ${ }^{1}$, Dimitrios Bougiouklis ${ }^{2}$, Paul Zarogoulidis ${ }^{\circledR}{ }^{\bowtie}$, Konstantinos Porpodis ${ }^{1}$, Manolis \\ Xristoforidis ${ }^{3}$, Alexandra Liaka ${ }^{1}$, Ellada Eleutheriadou ${ }^{1}$, Sofia Lampaki ${ }^{1}$, George Lazaridis ${ }^{4}$, John \\ Organtzis ${ }^{1}$, George Kyriazis ${ }^{1}$, Wolfgang Hohenforst-Schmidt ${ }^{5}$, Katerina Tsirgogianni ${ }^{1}$, Vasilis Karavasilis ${ }^{6}$, \\ Sofia Baka7, Kaid Darwiche ${ }^{8}$, Lutz Freitag8, Georgia Trakada9 ${ }^{9}$ Konstantinos Zarogoulidis ${ }^{1}$ \\ 1. Pulmonary Department-Oncology Unit, "G. Papanikolaou” General Hospital, Aristotle University of Thessaloniki, Thessaloniki, Greece; \\ 2. Gene and Cell Therapy Center, Hematology - BMT Unit, "G. Papanikolaou" Hospital, Thessaloniki, Greece; \\ 3. Surgical Department "G. Papanikolaou" General Hospital, Aristotle University of Thessaloniki, Thessaloniki, Greece; \\ 4. Oncology Department, "G. Papageorgiou” Hospital, Thessaloniki, Greece. \\ 5. II Medical Department, Regional Hospital of "Coburg", Coburg, Germany. \\ 6. Oncology Department, “G. Papageorgiou” University Hospital, Aristotle University of Thessaloniki, Thessaloniki, Greece. \\ 7. Oncology Department, "Interbalkan" European Medical Center, Thessaloniki, Greece. \\ 8. University Pulmonary Department-Interventional Unit, University of Duisburg-Essen, Essen, Germany. \\ 9. Department of Clinical Therapeutics, Division of Pulmonology, Medical School, National University of Athens, Athens, Greece.
}

$\triangle$ Corresponding author: Paul Zarogoulidis, M.D, PhD. Pulmonary Department-Oncology Unit, “G. Papanikolaou” General Hospital, Aristotle University of Thessaloniki, Thessaloniki, Greece. Fax: 00302310992433 Mobile: 00306977271974 E-mail: pzarog@hotmail.com.

() 2015 Ivyspring International Publisher. Reproduction is permitted for personal, noncommercial use, provided that the article is in whole, unmodified, and properly cited. See http://ivyspring.com/terms for terms and conditions.

Received: 2014.12.10; Accepted: 2014.12.31; Published: 2015.02.23

\begin{abstract}
Purpose: Somatostatin is a peptide with a potent and broad antisecretory action, which makes it an invaluable drug target for the pharmacological management of pituitary adenomas and neuroendocrine tumors. Furthermore, somatostatin (SST) receptors (SSTR1, 2A and B, 3, 4 and 5) belong to the $G$ protein coupled receptor family and are overexpressed in tumors. Since, human small-cell lung cancer overexpresses somatostatin receptors (STTR), they could be legitimate targets for treating SCLC.The aim of this study was the evaluation of cytotoxicity of somatostatin in combination with several anticancer drugs in HTB-175 cell line (Small Cell Lung Cancer Cell line that expresses neuron specific enolase).

Methods: Docetaxel, Paclitaxel, Carboplatin, Cisplatin, Etoposide, Gemzar, Navelbine, Fluorouracil, Farmorubicin are the chemotherapeutic drugs that we used for the combination before and after adding somatostatin in SCLC cell culture. HTB-175 cell line was purchased from ATCC LGC Standards.At indicated time-point, $48 \mathrm{~h}$ after the combination, cell viability and apoptosis were measured with Annexin $V$ staining by flow cytometry.

Results: Flow cytometry showed that Docetaxel, Paclitaxel, Gemzar and Cisplatin induced apoptosis more when they were added before somatostatin, whereas etoposide induced apoptosis more after somatostatin treatment. Navelbine alone or in combination with somatostatin showed no differences in apoptosis. Farmorubicin showed equal toxicity in all combinations. Fluorouracil and Carboplatin induced apoptosis more when added alone in HTB-175 cell line. However, increased apoptosis was also observed when Carboplatin was administered before somatostatin in higher concentrations.

Conclusion: Our results indicated that depending on the drug, somatostatin treatment before or after chemotherapeutic drugs increased apoptosis in small cell lung cancer cells. We suggest that long acting somatostatin analogues could be used as additive and maintenance therapy in combination to antineoplastic agents in SCLC patients.
\end{abstract}

Key words: SCLC, somatostatin, lung cancer. 


\section{Introduction}

Small cell lung cancer as a very aggressive disease, is characterized by an early relapse, by a tendency towards drug resistance by a high incidence of metastasis and represents approximately $13 \%$ of all newly diagnosed lung cancers $[1,2]$. Despite the developments in diagnosis and treatment of lung cancer, in regard to SCLC there is no clear evidencethat any current chemotherapeutic or biological agent significantly improves response or survival. Currently, the median survival of patients with limited disease is 14-16 months, and 8-11 months for those with extensive disease, with $20-40 \%$ of patients with limited disease and $5 \%$ of patients with extensive disease alive at 2 years [1].Therefore, there is an imperative need for a novel approach for the management of SCLC.

Since SCLC cells are of neuroendocrine origin and express high levels of somatostatin receptors, they could be legitimate targets for treating SCLC. Somatostatin (SST) receptors (SSTR1, 2A and B, 3, 4 and 5) belong to the G-protein coupled receptor family. About $80-100 \%$ of all SCLC cells express somatostatin receptor subtype 2 (SSTR2) [2].

In specific, somatostatin, (somatotropine release inhibiting factor, SRIF) is a regulatory-inhibitory peptide with exocrine, endocrine, paracrine and autocrine activity [3]. Many scientists have characterized somatostatin as the universal endocrine off switch [1]. A commentary has summarized the effects of somatostatin on cancer cells through different mechanisms, including: (a) normal endocrine activity via the GH-IGF1 axis, (b) inhibition of angiogenesis, (c) modulation of the immune response to tumor cells and (d) direct antiproliferative effect signaling on tumor cells via somatostatin receptors [6] due to either cell cycle arrest or induction of apoptosis [4]. It is known that somatostatin analogues inhibit in vitro cell proliferation via specific membrane receptors (SSTRs). Currently, two somatostatin analogues octreotide and lanreotide, are successfully used clinically for the treatment of acromegaly and gastroenteropancre-atic endocrine tumors $[5,6]$. These analogues bind preferentially to SSTR 2 and SSTR 5 with moderate affinity for SSTR 3 and low affinities for SSTR 1 and SSTR $4[7,8]$.

Besides, somatostatin receptor scintigraphycan be used to visualize primary tumours and metastases $[9,10]$. In addition, somatostatin analogues labeled with111indium, after appropriate modifications can be used as a vehicle of either chemotherapeutic or radioactive agents for the treatment of SSTRs positive tumors [11]. Furthermore, radiolabelled somatostatin analogues have been tested as a single therapy for
SCLC, but this has not been as promising as predicted, based on preclinical study results [12-14]. However, the number of clinical studies and the number of patients in those studies have been relatively limited, and the treatment protocol was not optimized for those patients $[15,16]$.

Recently, a clinical phase II/III study by Zarogoulidis et al compared the survival, feasibility and toxicity between patients that were treated with chemotherapy (CHT) alone (Group A - control group), with CHT plus $30 \mathrm{mg}$ lanreotide (somatuline ${ }^{\circledR}$, IPSEN) (Group B) and with CHT plus $60 \mathrm{mg}$ lanreotide (somatuline ${ }^{\circledR}$ auto-gel) (Group C), favoring these combinations and suggesting further research in targeted therapy and in downstream signaling events within cancer cells [3].

The aim of this study was the evaluation of cytotoxicity of somatostatin in combination with several anticancer drugs in a Small Cell Lung Cancer Cell line that expresses neuron specific enolase.

\section{Materials and Methods \\ Cell cultures and reagents}

NCI-H82 [H82] (ATCC® HTB-175 ${ }^{\mathrm{TM}}$ ) was purchased from ATCC LGC Standards.HTB-175 cell line was isolated from a 40-year-old male (http://www.lgcstandards-atcc.org). This line is a biochemical and morphological variant of SCLC that expresses neuron specific enolase that aggregates in suspension. The cells grow in very large aggregates, and the aggregates are the only viable cell population. HTB-175 cells were cultured in Dulbecco's Modified Eagle's Medium (DMEM) culture medium (ATCC-30-2001) supplemented with 10\% Fetal Bovine Serum (FBS) (Biochrom S0115). They were incubated at $37^{\circ} \mathrm{C}$ in a humidified atmosphere containing $5 \%$ $\mathrm{CO} 2$. Cell lines were cultured in Coming's tissue culture flasks $(25,75,225 \mathrm{~cm} 2)$ according to the manufacturer's protocol. After cultures reached confluence, by microscope observation were then subcultured. At indicated time-point. $48 \mathrm{~h}$ after somatostatin treatment, apoptosis was measured.

\section{Chemotherarapeutic agents}

Docetaxel $(10 \mathrm{mg} / \mathrm{ml}, 140 \mathrm{mg} / 5.5 \mathrm{~L})$, Paclitaxel $(1 \mathrm{mg} / \mathrm{ml}, 175 \mathrm{mg} / 5.5 \mathrm{~L})$, Carboplatin $(10 \mathrm{mg} / \mathrm{ml}, 350$ $\mathrm{mg} / 5.5 \mathrm{~L})$, Cisplatin $(1 \mathrm{mg} / \mathrm{ml}, 90 \mathrm{mg} / 5.5 \mathrm{~L})$, Etoposide $(20 \mathrm{mg} / \mathrm{ml}, \quad 400 \mathrm{mg} / 5.5 \mathrm{~L}), \quad$ Gemzar $\quad(40 \mathrm{mg} / \mathrm{ml}$, $2500 \mathrm{mg} / 5.5 \mathrm{~L})$, Navelbine $(10 \mathrm{mg} / \mathrm{ml}, 50 \mathrm{mg} / 5.5 \mathrm{~L})$, Fluorouracil $(50 \mathrm{mg} / \mathrm{ml}, 1000 \mathrm{mg} / 5.5 \mathrm{~L})$, Farmarubicin $(2 \mathrm{mg} / \mathrm{ml}, 70 \mathrm{mg} / 5.5 \mathrm{~L})$ are the chemotherapeutic drugs that we combined with somatostatin (Somargen, $3 \mathrm{mg} / \mathrm{ml}$ ) treatment in different concentrations. The best concentration of somatostatin proved to be $10 \mathrm{ul}$ in $15 \mathrm{ml}$ of culture medium. 
Firstly, all chemotherapeutic agents were added alone. Secondly chemotherapeutic agents were administered before somatostatin and third after somatostatin treatment. In these flasks, somatostatin was then added and incubated for 48 hours (Table 1).The $24 \mathrm{~h}$ incubation showed that it was not enough time to induce satisfactory apoptosis.

Table 1. Protocol of the experiment.

Incubation of the drugs in HTB-175 cell culture

1 Chemotherapeutic agent alone for $2 \mathrm{~h}$

Chemotherapeutic agent for $2 \mathrm{~h}$, washing, adding somatostatin for $48 \mathrm{~h}$

Somatostatin alone for $2 \mathrm{~h}+$ chemotherapeutic agent for $2 \mathrm{~h}$, washing, adding somatostatin for $48 \mathrm{~h}$

\section{Analysis of the apoptotic cells with ANNEXIN VI PI}

Annexin V staining is used as a probe to detect cells that have expressed phosphatidylserine (PS) on the cell surface, an event found in apoptosis as well as other forms of cell death. Propidium iodide (PI) is used as a DNA stain for both flow cytometry, to evaluate cell viability or DNA content in cell cycle analysis [17], and microscopy to visualize the nucleusand other DNA containing organelles. It can be usedto differentiate necrotic, apoptotic and normal cells. The Annexin V kit used in this study was purchased from ImmunostepCompany (Spain) and the analyses of the samples were performed in BD FACSCalibur 4colors, with CELLQUEST software (BECTON-DICKINSON USA). After the $48 \mathrm{~h}$ incubation of somatostatin, cells were collected by centrifuge for $3 \mathrm{~min}$ in 1.100rpm. $100 \mathrm{ul}$ of cell suspension (concentration 3000 to 5000 cells/ uL) were added to 500 $\mathrm{uL}$ of Annexin binding buffer. Then $5 \mathrm{uL}$ of Annexin $\mathrm{V}$ and $5 \mathrm{uL}$ PI were added to this solution and it was incubated for $15 \mathrm{~min}$ in a dark place at room temperature. Then it was analyzed in the flow cytometer (Table 1, Table 2, and Figure 1).

\section{Results}

Flow cytometry showed that Docetaxel, Paclitaxel, Gemzar and Cisplatin induced apoptosis more when they were added before somatostatin, whereas etoposide induced apoptosis more after somatostatin treatment. Navelbine alone or in combination with somatostatin showed no differences in apoptosis. Farmorubicin showed equal toxicity in all combinations. Fluorouracil and Carboplatin induced apoptosis more when added alone in HTB-175 cell line. However, increased apoptosis was also observed when Carboplatin was administered before somatostatin in higher concentrations (Table 2, Table 3 and Figure 1).

\section{Discussion}

Although some evidence supports the antitumor effects of somatostatin (SRIF) and related agonists, the available data in SCLC model systems and clinical studies are few, conflicting and not conclusive.

The National Comprehensive Cancer Network practice guidelines for the first-line treatment of SCLC named the etoposide-cisplatin (EC) regimen as the treatment of choice to be used concurrently with radiotherapy [18-21]. Platinum analogues (carboplatin, cisplatin) plus etoposide has been the standard chemotherapy for SCLC for decades. Alternatively, taxanes (paclitaxel and docetaxel) and platinum analogues include other treatment strategy. Furthermore, farmorubicin, and Vinca alkaloids are chemotherapeutic agents used in combination with other drugs in the treatment of SCLC. Currently, a Vinca alkaloid agent is Navelbine. In our study we combined several agents with somatostatin. The results revealed that depending on the drug, some induce apoptosis more when they are added before somatostatin (docetaxel, paclitaxel, gemzar, cisplatin) and some after (etoposide). This could be propably explained by a direct antiproliferative effect of somatostatin analogues that might enhance chemotherapy activity or by an immunoregulatory activity of somatostatin analogues on tumor cells [22].

Table 2. Cell viability and apoptosis with Annexin V/PI by flow cytometry 48h after somatostatin was added.

\begin{tabular}{|c|c|c|c|c|c|c|}
\hline \multirow[t]{2}{*}{ Chemotherapeutic Agent } & \multicolumn{2}{|c|}{ Chemotherapeutic Agent only } & \multicolumn{2}{|c|}{$\begin{array}{l}\text { Chemotherapeutic Agent added first, soma- } \\
\text { tostatin later }\end{array}$} & \multicolumn{2}{|c|}{$\begin{array}{c}\text { Somatostatin added first, before adding chemo- } \\
\text { therapeutic agent }\end{array}$} \\
\hline & \%Viability & $\%$ late apoptotic + dead cells & \%Viability & $\%$ late apoptotic + dead cells & \%Viability & $\%$ late apoptotic + dead cells \\
\hline Docetaxel & 26 & $14+60$ & 15 & $12+73$ & 20 & $16+63$ \\
\hline Paclitaxel & 29 & $14+55$ & 18 & $52+24$ & 23 & $44+28$ \\
\hline Cisplatin & 24 & $22+54$ & 23 & $13+63$ & 27 & $15+57$ \\
\hline Carboplatin & 33 & $9+58$ & 35 & $14+50$ & 33 & $12+54$ \\
\hline Etoposide & 29 & $14+57$ & 28 & $23+47$ & 20 & $20+59$ \\
\hline Navelbine & 35 & $18+45$ & 35 & $14+49$ & 35 & $14+49$ \\
\hline Farmorubicin & 15 & $77+18$ & 16 & $70+15$ & 16 & $64+18$ \\
\hline Fluorouracil & 37 & $51+12$ & 49 & $35+15$ & 45 & $28+27$ \\
\hline Gemzar & 34 & $18+47$ & 29 & $32+34$ & 33 & $11+55$ \\
\hline
\end{tabular}




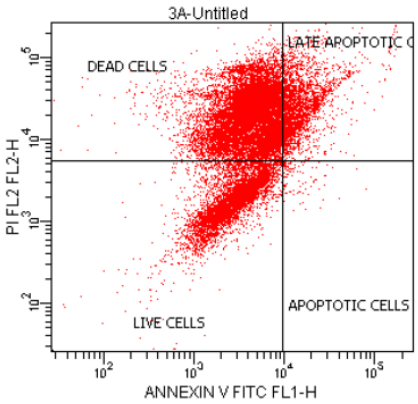

Docetaxel alone

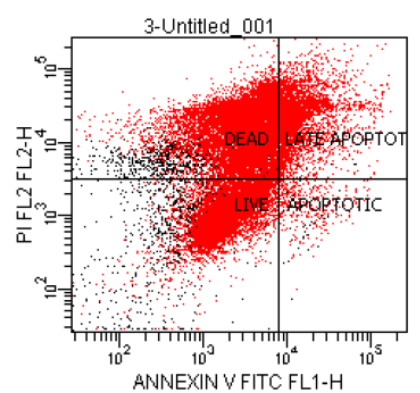

Paclitaxel alone

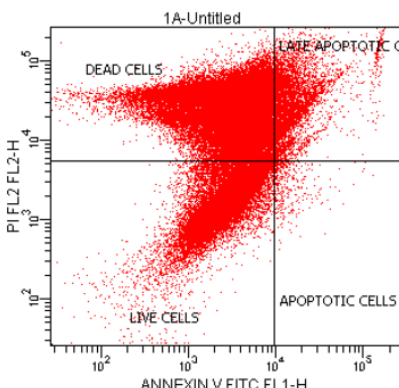

Carboplatin alone

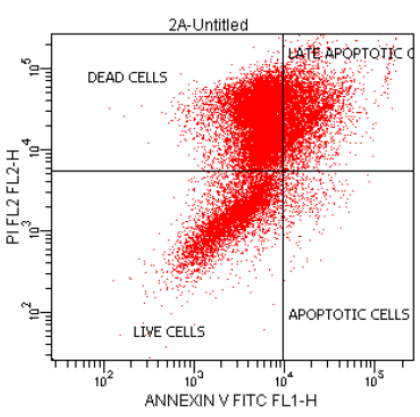

Cisplatin alone

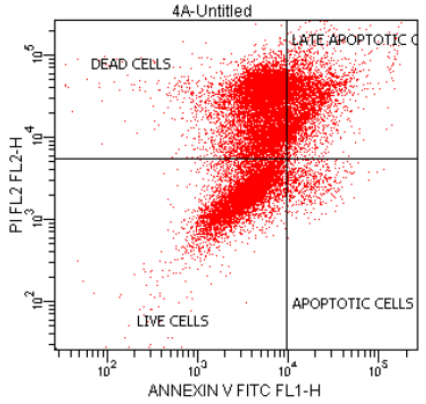

Navelbine alone

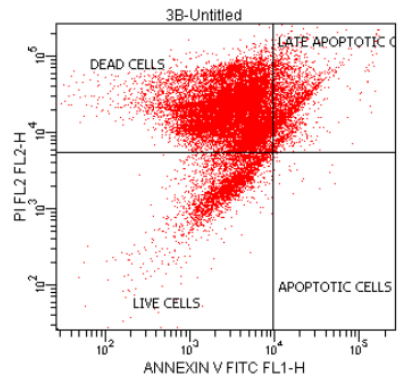

Docetaxel + somatostatin

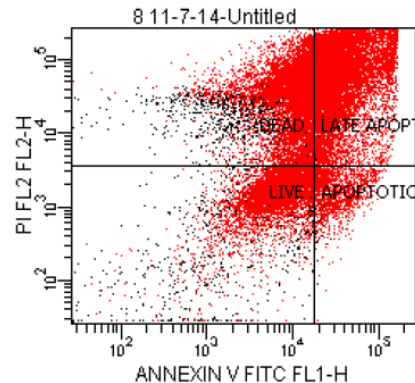

Paclitaxel + somatostatin

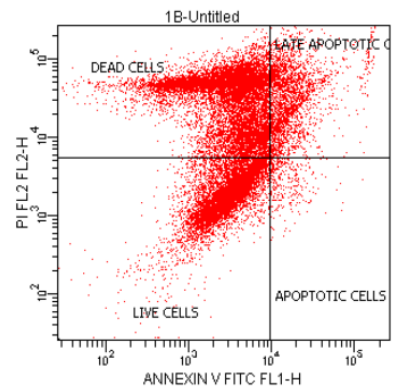

Carboplatin + Somatostatin

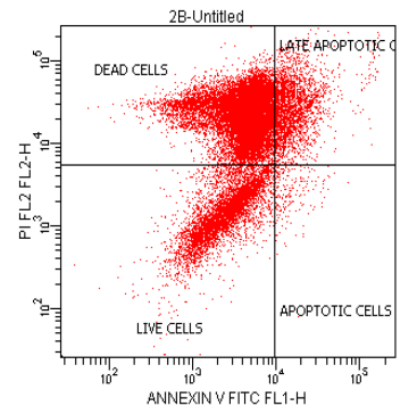

Cisplatin + Somatostatin

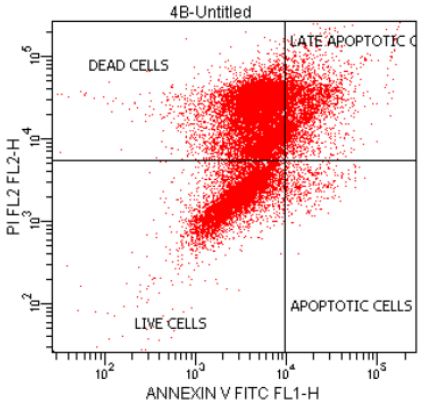

Navelbine + Somatostatin

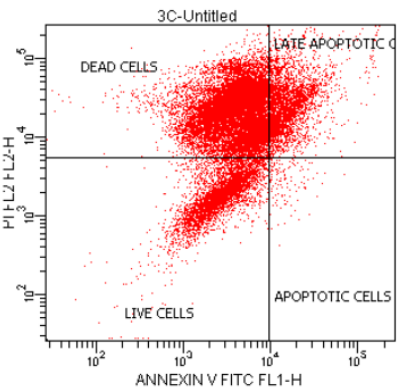

Somatostatin + Docetaxel + Somatostatin

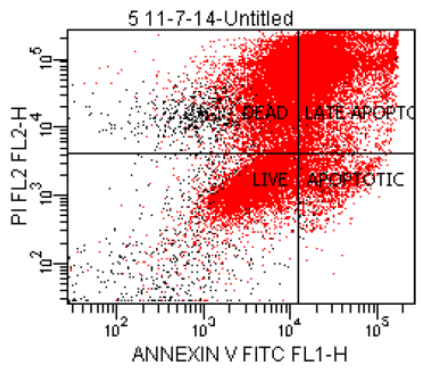

Somatostatin + Paclitaxel + Somatostatin

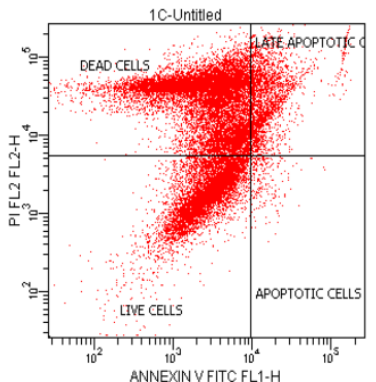

Somatostatin + Carboplatin + Somatostatin

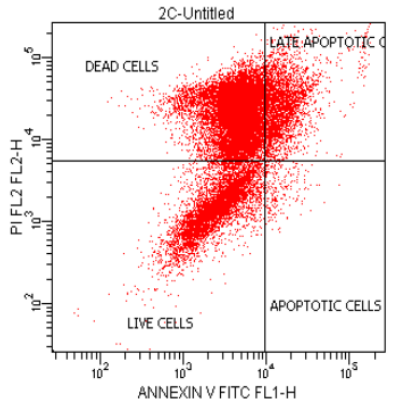

Somatostatin + Cisplatin + Somatostatin

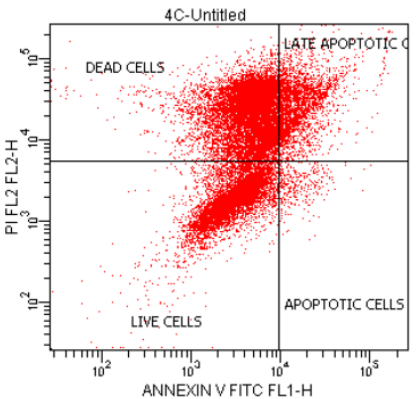

Somatostatin + Navelbine + Somatostatin 

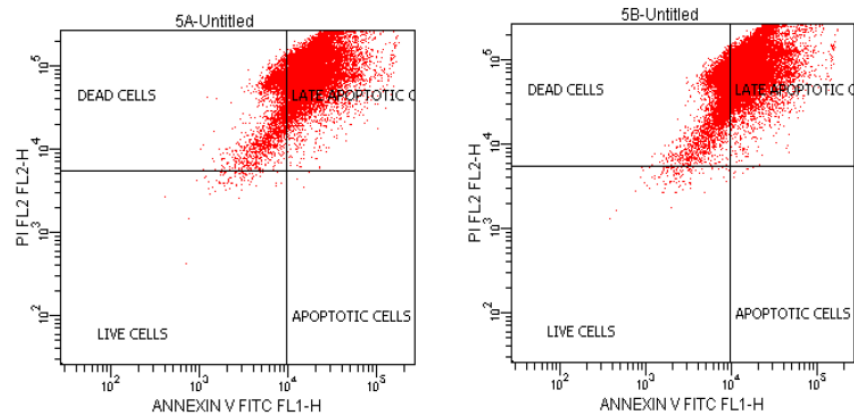

Farmorubicin alone

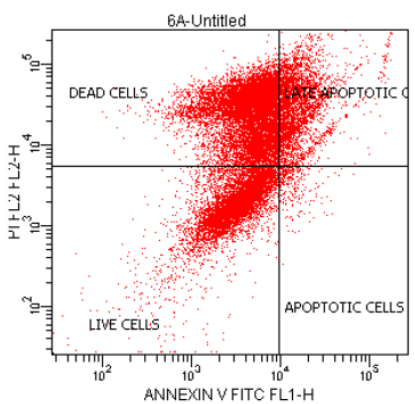

Gemzar alone

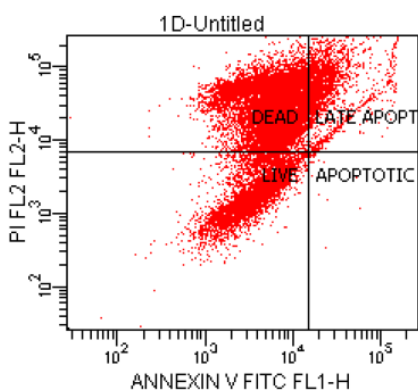

Etoposide alone

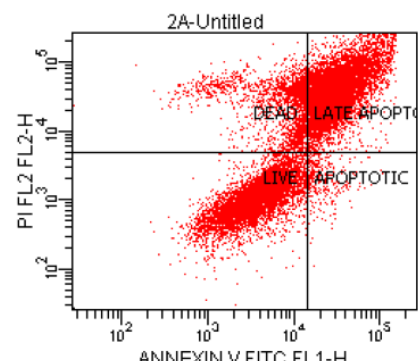

Fluorouracil alone
Farmorubicin + Somatostatin

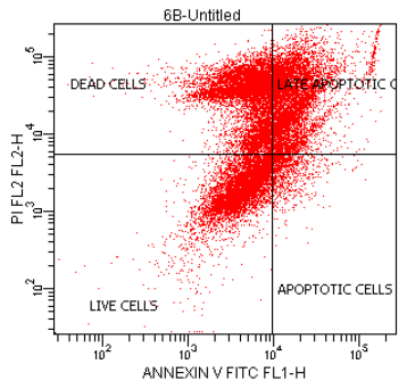

Gemzar + Somatostatin

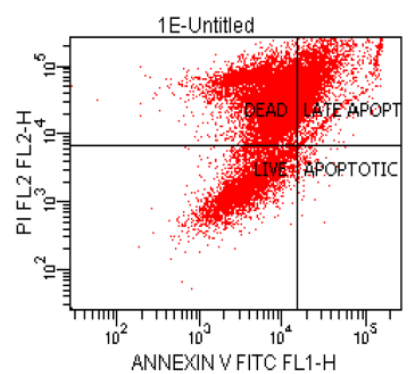

Etoposide + Somatostatin

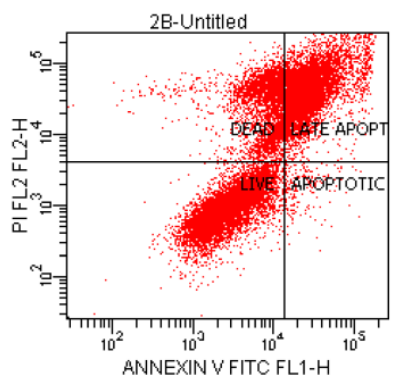

Fluorouracil + Somatostatin

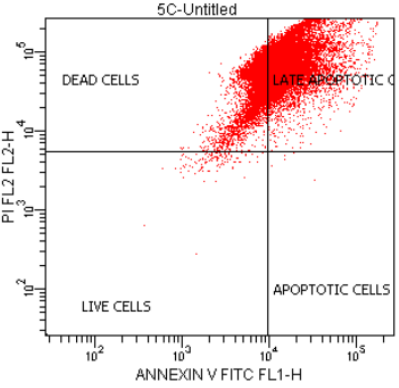

Somatostatin + Farmorubicin + Somatostatin

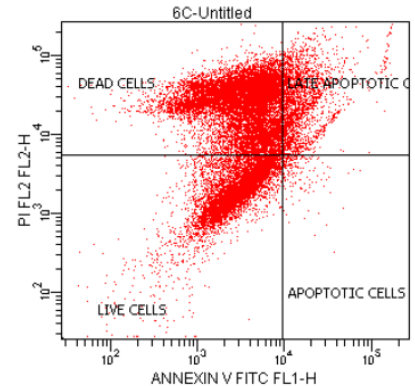

Somatostatin + Gemzar + Somatostatin

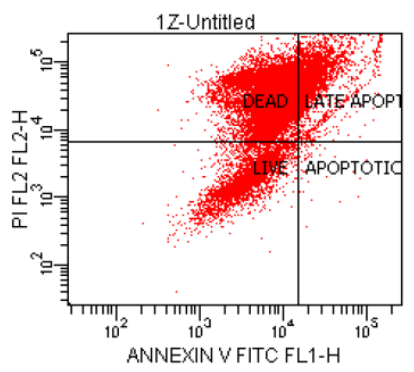

Somatostatin + Etoposide + Somatostatin

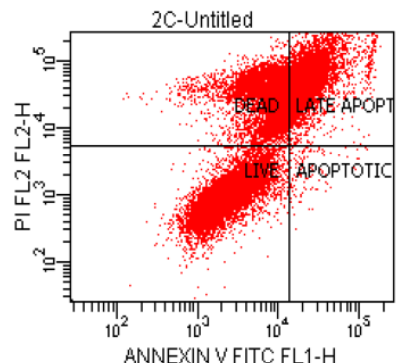

Somatostatin + Fluorouracil + Somatostatin
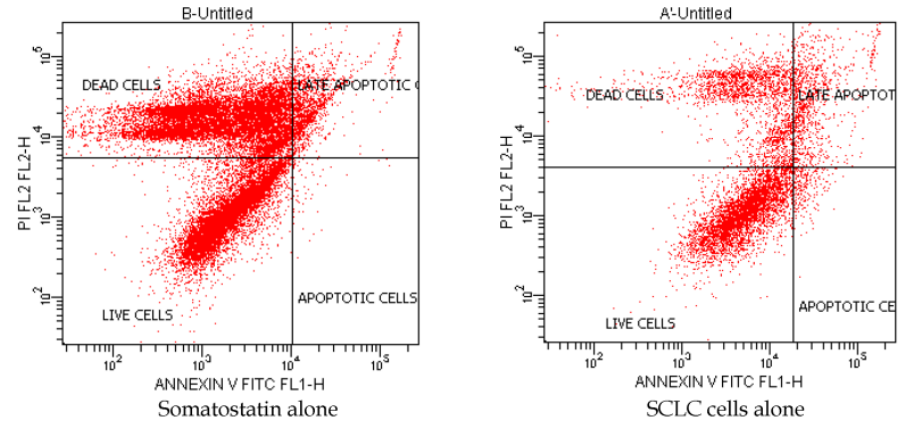

Figure 1. Cell viability and apoptosis with Annexin V/PI by flow cytometry. 
Table 3. Cell viability and apoptosis with Annexin V/PI by flow cytometry in control flasks.

\begin{tabular}{ll}
\hline flasks & \%Viability \\
\hline SCLC cells & 60 \\
Somatostatin added in SCLC cells & 43
\end{tabular}

Similarly, in vitro studies with somatostatin analogues such as lanreotide suggest that lanreotide given alone or in combination with cisplatin could have a therapeutic potential in the treatment of somatostatin receptor positive SCLC patients [23]. However, $\mathrm{Hu}$ et al reported that in gastric cancer cells that expressed SSTR3, octreotide could be effective in inhibiting cell growth and inducing cell apoptosis through mediation of SSTR3 [24].

As chemotherapy affects the immunedefense system of the host, Zarogoulidis et al suggested that somatostatin treatment combination might enhance the capability of the SCLC patient to repair their immune system between chemotherapy cycles. On the other hand they concluded that lanreotide stimulation for a longer period ( $>2$ weeks) seems to influence proliferation by delaying cell division that tumor cells are less sensitive to chemotherapy (resistant). Although somatostatin and its analogs hold promise as new agents in cancer treatment, there are limitations $[8,25]$.

However, recent research studies [26-28] have yielded important clinical benefits and promising therapeutic interventions with targeted therapies, but research is needed in targeted therapy and downstream signaling events within cancer cells. Successful targeted treatments mean better understanding of the signaling process of cancer receptors pathways, resulting in fewer side effects and increase of survival benefit. The better we understand the pathways through which the targeted therapies work (such as involved signaling pathways and their interrelationships), the better we will understand the potential of the targeted therapies. Thus, much work needs to be done to discern which somatostatin analog(s) preferentially bind which SSTR subtype(s) to be effective against which cancer(s) by which mechanism(s).

\section{Conclusion}

Long acting somatostatin analogues could be used as additive and maintenance therapy in combination to antineoplastic agents and might enhance the chemotherapeutic outcome indeed. We believe that intravenous administration a long acting somatostatin analog should be the method of treatment.

\section{Conflict of Interest}

None to declare.

\section{References}

1. Tartarone A, Lerose R, Ardito R, Troiani L, Tedesco B, Bozza G, et al. Long-term survival in small cell lung cancer: a case report and review of the literature. Future Oncol. 2014; 10: 523-8. doi:10.2217/fon.13.213.

2. Erlandsson A, Forssell-Aronsson E, Seidal T, Bernhardt P. Binding of TS1, an anti-keratin 8 antibody, in small-cell lung cancer after 177Lu-DOTA-Tyr3-octreotate treatment: a histological study in xenografted mice. EJNMMI research. 2011; 1: 19. doi:10.1186/2191-219X-1-19.

3. Zarogoulidis K, Eleftheriadou E, Kontakiotis T, Gerasimou G, Zarogoulidis P, Sapardanis I, et al. Long acting somatostatin analogues in combination to antineoplastic agents in the treatment of small cell lung cancer patients. Lung Cancer. 2012; 76: 84-8. doi:10.1016/j.lungcan.2011.09.014.

4. Arvigo M, Gatto F, Ruscica M, Ameri P, Dozio E, Albertelli M, et al. Somatostatin and dopamine receptor interaction in prostate and lung cancer cell lines. The Journal of endocrinology. 2010; 207: 309-17. doi:10.1677/JOE-10-0342

5. de Jong M, Breeman WA, Bernard BF, Bakker WH, Schaar M, van Gameren A, et al. [177Lu-DOTA(0),Tyr3] octreotate for somatostatin receptor-targeted radionuclide therapy. International journal of cancer Journal international du cancer. 2001; 92: 628-33.

6. Kwekkeboom DJ, Bakker WH, Kam BL, Teunissen JJ, Kooij PP, de Herder WW, et al. Treatment of patients with gastro-entero-pancreatic (GEP) tumours with the novel radiolabelled somatostatin analogue [177Lu-DOTA(0),Tyr3]octreotate. European journal of nuclear medicine and molecular imaging. 2003; 30: 417-22. doi:10.1007/s00259-002-1050-8.

7. Weckbecker G, Raulf F, Stolz B, Bruns C. Somatostatin analogs for diagnosis and treatment of cancer. Pharmacology \& therapeutics. 1993; 60: 245-64.

8. Weckbecker G, Lewis I, Albert R, Schmid HA, Hoyer D, Bruns C. Opportunities in somatostatin research: biological, chemical and therapeutic aspects. Nature reviews Drug discovery. 2003; 2: 999-1017. doi:10.1038/nrd1255.

9. Kwekkeboom DJ, Kho GS, Lamberts SW, Reubi JC, Laissue JA, Krenning EP. The value of octreotide scintigraphy in patients with lung cancer. European journal of nuclear medicine. 1994; 21: 1106-13.

10. Forssell-Aronsson E, Bernhardt P, Nilsson O, Tisell LE, Wangberg B, Ahlman $\mathrm{H}$. Biodistribution data from 100 patients i.v. injected with 111In-DTPA-D-Phe1-octreotide. Acta Oncol. 2004; 43: 436-42.

11. Smith MC, Liu J, Chen T, Schran H, Yeh CM, Jamar F, et al. OctreoTher: ongoing early clinical development of a somatostatin-receptor-targeted radionuclide antineoplastic therapy. Digestion. 2000; 62 Suppl 1: 69-72. doi:51858.

12. Schmitt A, Bernhardt P, Nilsson O, Ahlman H, Kolby L, Schmitt J, et al Biodistribution and dosimetry of 177Lu-labeled [DOTA0,Tyr3]octreotate in male nude mice with human small cell lung cancer. Cancer biotherapy \& radiopharmaceuticals. 2003; 18: 593-9. doi:10.1089/108497803322287682.

13. Schmitt A, Bernhardt P, Nilsson O, Ahlman H, Kolby L, Maecke HR, et al. Radiation therapy of small cell lung cancer with 177Lu-DOTA-Tyr3-octreotate in an animal model. Journal of nuclear medicine : official publication, Society of Nuclear Medicine. 2004; 45: 1542-8.

14. Schmitt A, Bernhardt P, Nilsson O, Ahlman H, Kolby L, Forssell-Aronsson E. Differences in biodistribution between $99 \mathrm{mTc}$-depreotide, 111In-DTPA-octreotide, and 177Lu-DOTA-Tyr3-octreotate in a small cell lung cancer animal model. Cancer biotherapy \& radiopharmaceuticals. 2005; 20: 231-6. doi:10.1089/cbr.2005.20.231.

15. Pless $M$, Waldherr C, Maecke H, Buitrago C, Herrmann R, Mueller-Brand J. Targeted radiotherapy for small cell lung cancer using 90Yttrium-DOTATOC, an Yttrium-labelled somatostatin analogue: a pilot trial. Lung Cancer. 2004; 45: 365-71. doi:10.1016/j.lungcan.2004.02.020.

16. van Essen M, Krenning EP, Kooij PP, Bakker WH, Feelders RA, de Herder WW, et al. Effects of therapy with [177Lu-DOTA0, Tyr3] octreotate in patients with paraganglioma, meningioma, small cell lung carcinoma, and melanoma. Journal of nuclear medicine : official publication, Society of Nuclear Medicine. 2006; 47: 1599-606.

17. Van Hooijdonk CA, Glade CP, Van Erp PE. TO-PRO-3 iodide: a novel HeNe laser-excitable DNA stain as an alternative for propidium iodide in multiparameter flow cytometry. Cytometry. 1994; 17: 185-9. doi:10.1002/cyto.990170212.

18. Murray N, Turrisi AT, 3rd. A review of first-line treatment for small-cell lung cancer. Journal of thoracic oncology : official publication of the International Association for the Study of Lung Cancer. 2006; 1: 270-8.

19. Rossi A, Martelli O, Di Maio M. Treatment of patients with small-cell lung cancer: from meta-analyses to clinical practice. Cancer treatment reviews. 2013; 39: 498-506. doi:10.1016/j.ctrv.2012.09.006.

20. Domvri K, Zarogoulidis P, Darwiche K, Browning RF, Li Q, Turner JF, et al. Molecular Targeted Drugs and Biomarkers in NSCLC, the Evolving Role of Individualized Therapy. J Cancer. 2013; 4: 736-54. doi:10.7150/jca.7734 jcav04p0736 [pii].

21. Porpodis K, Karanikas M, Zarogoulidis P, Kontakiotis T, Mitrakas A, Esebidis A, et al. A case of typical pulmonary carcinoid tumor treated with 
bronchoscopic therapy followed by lobectomy. J Multidiscip Healthc. 2012; 5: 47-51. doi:10.2147/JMDH.S29709 jmdh-5-047 [pii].

22. Grimberg A. Somatostatin and cancer: applying endocrinology to oncology. Cancer biology \& therapy. 2004; 3: 731-3.

23. Prevost G, Bourgeois $Y$, Mormont C, Lerrant $Y$, Veber N, Poupon MF, et al. Characterization of somatostatin receptors and growth inhibition by the somatostatin analogue BIM23014 in small cell lung carcinoma xenograft: SCLC-6. Life sciences. 1994; 55: 155-62.

24. Hu C, Yi C, Hao Z, Cao S, Li H, Shao X, et al. The effect of somatostatin and SSTR3 on proliferation and apoptosis of gastric cancer cells. Cancer biology \& therapy. 2004; 3: 726-30.

25. Hejna $\mathbf{M}$, Schmidinger $\mathbf{M}$, Raderer $\mathbf{M}$. The clinical role of somatostatin analogues as antineoplastic agents: much ado about nothing? Annals of oncology : official journal of the European Society for Medical Oncology / ESMO. 2002; 13: 653-68.

26. Gatzemeier U, Pluzanska A, Szczesna A, Kaukel E, Roubec J, De Rosa F, et al. Phase III study of erlotinib in combination with cisplatin and gemcitabine in advanced non-small-cell lung cancer: the Tarceva Lung Cancer Investigation Trial. Journal of clinical oncology : official journal of the American Society of Clinical Oncology. 2007; 25: 1545-52. doi:10.1200/JCO.2005.05.1474.

27. Herbst RS, Prager D, Hermann R, Fehrenbacher L, Johnson BE, Sandler A, et al. TRIBUTE: a phase III trial of erlotinib hydrochloride (OSI-774) combined with carboplatin and paclitaxel chemotherapy in advanced non-small-cell lung cancer. Journal of clinical oncology : official journal of the American Society of Clinical Oncology. 2005; 23: 5892-9. doi:10.1200/JCO.2005.02.840.

28. Pirker R, Pereira JR, Szczesna A, von Pawel J, Krzakowski M, Ramlau R, et al. Cetuximab plus chemotherapy in patients with advanced non-small-cell lung cancer (FLEX): an open-label randomised phase III trial. Lancet. 2009; 373: 1525-31. doi:10.1016/S0140-6736(09)60569-9. 